\title{
Analisis Algoritma Apriori Untuk Mendukung Strategi Promosi Perguruan Tinggi
}

\author{
Haryo Kusumo ${ }^{1}$, Eko Sediyono ${ }^{2}$, Marwata Marwata ${ }^{3}$ \\ 123 Universitas Kristen Satya Wacana
}

\begin{abstract}
Every company or organization that wants to stay afloat needs to determine the effectiveness of the right promotional strategy. Determination of the right promotional strategy will be able to reduce the cost of promotion and achieve the right promotional goals. One way that can be done to determine the promotion strategy is to use data mining techniques. Data mining techniques used in this case are by using the Apriori algorithm. A priori algorithm is one of the classic data mining algorithms. A priori algorithm is used so that the computer can learn the rules of association, look for patterns of relationships between one or more items in a dataset. school origin, department, and study program chosen. The results of this study are in the form of an interesting pattern of data mining results which is important information to support the right promotion strategy in getting prospective new students.
\end{abstract}

Keywords: Apriori Alogarithms, Maining Data, Promotion Strategies, New Students

\begin{abstract}
Abstrak
Setiap perusahaan maupun organisasi yang ingin tetap bertahan perlu untuk menentukan pengefektifan strategi promosi yang tepat. Penentuan strategi promosi yang tepat akan dapat mengurangi biaya promosi dan mencapai sasaran promosi yang tepat. Salah satu cara yang dapat dilakukan untuk penentuan strategi promosi adalah dengan menggunakan teknik data mining.Teknik data mining yang digunakan dalam hal ini adalah dengan menggunakan algoritma Apriori. Algoritma apriori merupakan salah satu algoritma klasik data mining Algoritma apriori digunakan agar komputer dapat mempelajari aturan asosiasi, mencari pola hubungan antar satu atau lebih item dalam suatu dataset.Penelitian ini dilakukan dengan mengamati beberapa variabel penelitian yang sering dipertimbangkan oleh perguruan tinggi dalam menentukan sasaran promosinya yaitu asal sekolah, jurusan, dan prodi yang dipilih. Hasil penelitian ini adalah berupa pola menarik hasil data mining yang merupakan informasi penting untuk mendukung strategi promosi yang tepat dalam mendapatkan calon mahasiswa baru.
\end{abstract}

Kata Kunci : Alogaritma Apriori , Data Maining, Strategi Promosi, Mahasiswa Baru

ISSN 2715-0143 (online) ISSN 2714-9048 (print)

http://journal.walisongo.ac.id/index.php/jit/index 


\section{PENDAHULUAN}

Dewasa ini jumlah Perguruan Tinggi Swasta (PTS) meningkat pesat. Data yang didapat pada pangkalan data DIKTI yang ada di http://forlap.dikti.go.id/, saat ini mencapai 4.250 institusi, mulai dari akademi, sekolah tinggi, institut, hingga universitas (PDDIKTI, 2019). Perguruan Tinggi saat ini dituntut untuk memiliki keunggulan bersaing dengan memanfaatkan seluruh sumber daya yang dimiliki (Azimah \& Sucahyo, 2007). Tingginya tingkat persaingan antar institusi pendidikan mengakibatkan setiap institusi harus dapat mengelola institusinya secara profesional, seperti halnya sebuah perusahaan, Seperti layaknya sebuah organisasi, PTS membutuhkan sumber pendapatan untuk membiayai semua kegiatan dan program. Mahasiswa adalah sumber pendapatan utama bagi keberlangsungan PTS. Semua strategi akan dilakukan oleh sebuah PTS untuk mendapatkan mahasiswa sebanyak mungkin sesuai dengan kapasitas.

PTS harus menerapkan strategi promosi yang baik, agar dapat memenangkan persaingan dalam mendapatkan calon mahasiswa yang jumlahnya terbatas. Promosi merupakan hal yang sangat wajib dilakukan untuk menentukan sukses tidaknya suatu perusahaan, ataupun instansi yang lainnya (Suharyadi \& Sediyono, 2017). Pada instansi pendidikan promosi dapat dilakukan untuk menarik minat calon mahasiswa yang akan mendaftar pada perguruan tinggi khususnya di Sekolah Tinggi Elektronika dan
Komputer (STEKOM) Semarang. Banyaknya kegiatan yang dilakukan secara komputerisasi sekarang ini mempermudah dalam ketersediaan data. Namun data yang tersedia seringkali hanya diperlakukan sebagai rekaman (record) tanpa pengolahan lebih lanjut sehingga tidak bernilai lebih untuk keperluan masa mendatang. Bisnis dalam bidang apapun saat ini dituntut memiliki keunggulan bersaing dengan memanfaatkan semua sumber daya yang dimiliki. Pelaku bisnis harus mampu melakukan proses evaluasi, perencanaan dan pengelolaan secara baik untuk dapat memenangkan persaingan di era globalisasi ini .

Teknologi informasi dapat digunakan untuk mendapatkan, mengolah dan menyebarkan informasi untuk menunjang kegiatan operasional sehari-hari sekaligus menunjang kegiatan pengambilan keputusan strategis yang pada akhirnya dapat meningkatkan keunggulan bersaing. Penggunaan Sistem Infomasi sangat membantu sebuah instansi dalam menentukan kebijakan, seperti pemilihan karyawan dengan mengklasifikasi agar mendapatkan hasil sesuai yang diharapkan yaitu dapat meminimalisir kecurangan dengan mendapatkan karyawan yang berkualitas (Febryantahanuji, Sembiring, \& Purnomo, 2018). Teknik yang dikenal dengan data mining dapat menghasilkan informasi yang bermanfaat tersebut. Data mining adalah serangkaian proses untuk menggali nilai tambah dari suatu kumpulan data berupa pengetahuan yang selama ini tidak diketahui secara 
manual (Iko, 2006). Metodologi penelitian data mining pada prinsipnya merupakan kegiatan pencarian pengetahuan atau lebih dikenal dengan Knowledge Discovery (Rumaisa, 2012). Perkembangan dalam teknologi pengumpulan dan penyimpanan data yang cepat telah memudahkan institusi dan berbagai organisasi untuk mengumpulkan sejumlah data berukuran besar sehingga menghasilkan gunung data, ekstraksi informasi yang berguna dari gunung data menjadi pekerjaan yang cukup menantang (Yani \& Jusia, 2018). Penggalian dan penambangan mencakup berbagai algoritma seperti pengelompokan, klasifikasi, penambangan aturan asosiasi dan deteksi urutan. Secara tradisional, semua algoritma ini telah dikembangkan dalam model terpusat, dengan semua data dikumpulkan situs pusat, dan algoritma dijalankan terhadap data itu (Vaidya \& Clifton, 2002). Adapun teknik data mining pernah digunakan dalam promosi pada lingkungan Perguruan Tinggi Swasta (PTS) untuk membantu dalam meningkatkan jumlah mahasiswa yang mendaftar, sehingga efektifitas biaya dan tenaga dapat tercapai (Suharyadi \& Sediyono, 2017).

Metode yang akan digunakan pada penelitian ini adalah metode association rules dengan menggunakan algoritma apriori, yaitu algoritma untuk menemukan pola frekuensi tinggi. Association rule yang dimaksud dilakukan melalui mekanisme penghitungan support dan confidence dari suatu hubungan item. Algoritma Apriori sudah digunakan di beberapa penelitian sebelumnya, namun belum ada yang menggunakannya untuk penentuan rule pemilihan program studi calon mahasiswa (Rumaisa, 2012). Algoritma apriori ini akan cocok untuk diterapkan bila terdapat beberapa hubungan item yang ingin dianalisa. Salah satunya yang bisa diterapkan adalah di dalam bidang promosi dan penentuan strategi pemasaran (Kurniawati, 2014)

Penelitian ini akan mempermudah dalam menemukan pola frequensi untuk menentukan strategi promosi yang efektif dengan memanfaatkan data mahasiswa yang di olah lebih lanjut sehingga menghasilkan informasi untuk menekan pengeluaran dalam bidang promosi untuk menjaring mahasiswa baru di kampus STEKOM Semarang.

\section{METODE}

Metodologi penelitian merupakan langkah-langkah kerja yang perlu dilakukan agar penelitian ini menjadi lebih mudah.Penelitian merupakan rangkaian kegiatan ilmiah.Sebagai langkah awal maka perlu adanya studi literatur untuk menentukan metode data mining untuk pengolahan data dan penentuan alternatif solusi. Selanjutnya identifikasi masalah berkenaan dengan masalah yang dibahas, kemudian dilakukan pengumpulan data berkaitan dengan permasalahan yang akan diteliti, selanjutnya dilakukan pengumpulan data untuk menentukan parameter-parameter yang akan dijadikan landasan untuk melakukan penelitian ini. Secara umum proses- 
proses yang dilakukan dalam pelaksanaan penelitian ini sebagai berikut (gambar 1)

a) Studi literatur yang dilakukan untuk mendapatkan teori-teori tentang permasalahan yangtelah dirumuskan. Teori-teori ini berfungsi sebagai panduan untuk mendapatkan solusi.

b) Mengumpulkan data-data yang diperlukan untuk penelitian ini. Data didapat dari bagianakademik yang berupa data mahasiswa angkatan 2013 2018 dari 3 program studi yang telah dinyatakan lulus dari STEKOM Semarang. Data-data ini berisi data diri dari mahasiswa.

c) Data-data yang telah didapatkan kemudian dilanjutkan ke pra proses data mining. Tahap pertama adalah data cleaning. Pada tahap ini data-data yang memiliki atribut yang tidak lengkap atau kosong akan dihapus. Selanjutnya tahap data integration dimana data yangberjenis data nominal diinisialisasikan ke dalam bentuk angka dapat diolah dengan menggunakan algoritma Apriori. Tahap ini sejalan dengan proses task relevan data. Proses ini adalah seleksi atribut-atribut data yang dianggap relevan dengan rumusan masalah. Dalam penelitian ini hanya beberapa atribut data saja yang digunakan, seperti sekolah asal, jurusan sekolah, program studi. d) Semua data yang telah didapatkan tadi kemudian diolah dengan proses data mining. Pengolahan data ini menggunakan algoritma Apriori. Hasil proses ini adalah data yang dikelompokkan berdasar kemiripan karakteristik dari setiap data, sehingga dapat ditemukan pola atau informasi yang tersembunyi dari data-data tersebut.

e) Berdasarkan hasil tersebut, dilakukan knowledge presentation. Knowledge presentation yaitu menyajikan pola atau informasi yang ditemukan yang sesuai fakta atau hipotesa yang ada sebelumnya. Pola ini nantinya adalah pola yang berguna sebagai output penelitian ini. Output tersebut akan menjawab masalah yang telah dirumuskan di awalkarena pada proses ini dilakukan formulasi keputusan atau aksi dari hasil yang didapat. 


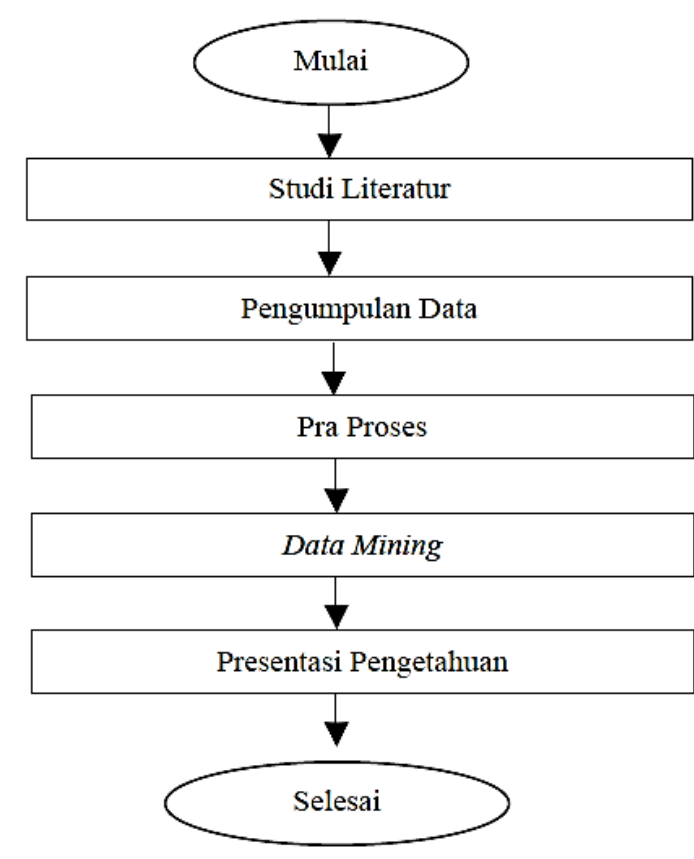

Gambar1

SkemaAlurTahapMetodePeneliti

an

\section{KERANGKA TEORI}

Fajar Rohman Hariri dan Risky Aswi Ramadhan dalam penelitiannya yang berjudul "Penerapan Data Mining menggunakan Association Rule Untuk Mendukung Strategi Promosi Universitas Nusantara PGRI Kediri". Penelitian kali ini akan mengimplementasikan metode Association Rule Apriori dalam menganaliasa hubungan daerah dan minat mahasiswa terhadap suatu prodi pada Universitas Nusantara PGRI Kediri, sehingga dapat memberikan rekomendasi wilayah promosi. Probabilitas tertinggi dengan nilai $72 \%$ adalah Teknik Informatika - Kediri. Sehingga dapat disimpukan bahwa untuk promosi di daerah Kediri, pihak UNP dapat menonjolkan prodi teknik Informatika karena banyak diminati di daerah tersebut (Risky, 2017).

Deden Prayitno dalam penelitiannya yang berjudul "Ekstraksi Pola Hubungan Penerimaan Mahasiswa Baru Dengan Sebaran Wilayah Asal Sekolah Menggunakan ARM Algoritma Apriori". Dengan mengetahui sebaran mahasiswa pada setiap program studi, tim dari biro pemasaran penerimaan mahasiswa baru dapat menggunakan informasi hasil penelitian ini untuk menjadi salah satu strategi dalam melakukan promosi ke sekolahsekolah. Urutan prioritas untuk promosi dilakukan utamanya di wilayah Jabodetabek adalah Jakarta, selanjutnya ke Bekasi, Bogor, Tanggerang dan Depok. Selanjutnya untuk diluar Jabodetabek adalah Jawa tengah, Jawa Timur, Jawa Barat dan Banten, dan pemasaran yang ada pada prioritas terakhir adalah diluar pulau Jawa (Prayitno, 2017).

Dwi Winarni dan Purwanti dengan judul penelitian "Analisis Data Mining Dengan Algoritma Fp-Growth Dalam Mendukung Strategi Promosi Perguruan Tinggi" penelitian ini membahas tentang Metode dalam pencarian Frequent Itemsset pohon keputusan menggunakan algoritma FPGrowth lebih efesien dalam melakukan Frequent Itemsset dengan proses pembentukan FP-Tree dengan menghasilkan rule dari data sampel calon mahasiswa baru di Universitas Dharmas Indonesia. Algoritma FPGrowth akan digunakan untuk mempercepat proses penentuan frequent itemset sebelum mengenerate rule sebagai rekomendasi 
keputusan. Dari hasil rule yang dihasilkan dapat diambil keputusan bahwa jurusan yang paling banyak diminati di Universitas Dharmas Indonesia adalah system informasi dan Pendidikan Guru SD (PGSD) dan ratarata yang berasal dari sekolah Swasta. Untuk Sistem Infomasi diminati calon Mahasiswa yang berasal dari jurusan IPA dan TKJ sedangkan PGSD diminati calon mahasiswa yang berasal dari jurusan IPS. Dengan hasil ini diharapkan dapat menjadi referensi dan strategi untuk mempromosikan semua prodi Di Universitas Dharmas Indonesia baik disekolah swasta maupun negri, dan SMA ataupun SMK (Purwanti, 2018).

\section{Algoritma Apriori}

Algoritma a-priori adalah suatu algoritma dasar yang diusulkan oleh Agrawal dan Srikant pada tahun 1994 untuk menentukan Frequent itemsets untuk aturan asosiasi Boolean. Algoritma A-priori termasuk jenis Aturan Asosiasi pada data mining (Luthfi, 2009) aturan yang menyatakan asosiasi antara beberapa atribut sering disebut affinity analysis atau market basket analysis.

Analisis asosiasi atau association rule mining adalah teknik data mining untuk menemukan aturan suatu kombinasi item serta berguna untuk menemukan hubungan tersembunyi yang menarik di data set yang besar (Kang, 2016). Salah satu tahap analisis asosiasi yang menarik perhatian banyak peneliti untuk menghasilkan algoritma yang efisien adalah analisis pola frequensi tinggi (frequent pattern mining). Penting tidaknya suatu asosiasi dapat diketahui dengan dua tolok ukur, yaitu : support dan confidence. Support (nilai penunjang) adalah persentase kombinasi item tersebut dalam database, sedangkan confidence (nilai kepastian) adalah kuatnya hubungan antara-item dalam aturan asosiasi.

a) Pola frekuensi tinggi

Pada tahap dimana pembentukan kombinasi antar item yang telah memenuhi syarat minimum support yang telah ditentukan sebelumnya. Nilai support pada satu itemset dapat diperoleh dengan menggunakan sebuah rumus di bawah ini:

$$
\begin{aligned}
& \text { Support(A) } \\
& =\frac{\text { jumlahTransaksiMengandung A }}{\text { NilaiTransaksi }}
\end{aligned}
$$

Rumus diatas memiliki arti untuk menentukan nilai support pada satu itemset jumlah transaksi yang mengandung item A dibagi dengan jumlah transaksi yang ada pada database.

Rumus nilai support 2 item :

$$
\begin{aligned}
& \text { Support }(\mathrm{A}, \mathrm{B})=\operatorname{Support}(\mathrm{A} \cap \mathrm{B}) \\
& =\frac{\text { jumlahTransaksiMengandungAdanB }}{\text { NilaiTransaksi }}
\end{aligned}
$$

Pada rumus diatas untuk menentukan nilai support pada dua itemset atau lebih, jumlah transaksi yang mengandung item A dan B dibagi 
dengan total transaksi yang terjadi pada dataset.

b) Pembentukan Aturan Asosiasi Langkah yang dilakukan setelah menentukan nilai support pada itemset berfrekuensi tinggi lalu dibentuk aturan asosiasi yang menyatakan kuatnya hubungan kombinasi itemset pada transaksi. Untuk menentukan aturan asosiasi yang terbentuk minimal itemset harus memiliki dua kandidat A dan B. Pada rules yang terbentuk berlaku hukum asosiatif A $\rightarrow$ B tidak berlaku B $\rightarrow$ A. Untuk menentukan aturan $\mathrm{A}->\mathrm{B}$ digunakan rumus:

confidence $=$ Support $(\mathrm{A} \mid \mathrm{B})$

$=\frac{\text { jumlahTransaksiMengandungAdan } B}{\text { jumlahTransaksimengandung } A}$

\section{PEMBAHASAN}

Dalam analisa ini penulis menganalisa dan mengelompok kelompok data untuk memudahkan dalam mengerjakan perancangan sistem yang telah direncanakan sebelumnya sesuai dengan variablevariabel yang dibutuhkan, guna untuk menganalisa data yang diperlukan dalam perancangan system ini.

Pada tahap ini peneliti melakukan pengelompokkan data yang dibutuhkan untuk menentukan bidan teladan. Data tersebut dikelompokkan kedalam :

a. Asal Sekolah

b. Jurusan Asal sekolah c. Prodi yang dipilih

Data yang sudah didapatkan belum bisa langsung diolah, data yang sudah dikumpulkan di-transformasikan dan diberikan kode agar mudah dalam pemrosesan atau pengolahan Data Mining.

Tabel 1. Tabel Pengkodean

\begin{tabular}{lll}
\hline No & Kode & Nama \\
\hline 1 & A1 & $\begin{array}{l}\text { SMA N 8 } \\
\text { SEMARANG }\end{array}$ \\
\hline 2 & A2 & $\begin{array}{l}\text { SMA N 1 } \\
\text { KALIWUNGU }\end{array}$ \\
\hline 3 & A3 & $\begin{array}{l}\text { SMA N 1 } \\
\text { LIMBANGAN }\end{array}$ \\
\hline 4 & A4 & SMK N 3 KENDAL \\
\hline 5 & A5 & SMK TEXMACO \\
6 & B1 & IPA \\
\hline 7 & B2 & IPS \\
8 & B3 & KEJURUAN \\
\hline 9 & C1 & KOMPUTER \\
& & AKUNTANSI \\
10 & C2 & DESAIN GRAFIS \\
11 & C3 & TI \\
\hline
\end{tabular}

Pada tahap ini dilakukan seleksi data yang memiliki atribut yang relevan. Dengan melakukan seleksi data akan membantu tahapan proses data mining dalam menemukan pola data yang berguna, yang merupakan proses transformasi. 
Tabel 2. Tabel Kombinasi

\begin{tabular}{ccccccccccc}
\hline A1 & A2 & A3 & A4 & A5 & B1 & B2 & B3 & C1 & C2 & C3 \\
\hline $\mathbf{0}$ & 1 & 0 & 0 & 0 & 1 & 0 & 0 & 1 & 0 & \\
$\mathbf{0}$ & 1 & 0 & 0 & 0 & 1 & 0 & 0 & 1 & 0 \\
$\mathbf{0}$ & 1 & 0 & 0 & 0 & 1 & 0 & 0 & 1 & 0 \\
$\mathbf{0}$ & 1 & 0 & 0 & 0 & 1 & 0 & 0 & 1 & 0 \\
$\mathbf{0}$ & 1 & 0 & 0 & 0 & 1 & 0 & 0 & 1 & 0 \\
$\mathbf{0}$ & 1 & 0 & 0 & 0 & 1 & 0 & 0 & 1 & 0 \\
$\mathbf{0}$ & 1 & 0 & 0 & 0 & 1 & 0 & 0 & 1 & 0 \\
$\mathbf{0}$ & 1 & 0 & 0 & 0 & 1 & 0 & 0 & 1 & 0 \\
$\mathbf{0}$ & 1 & 0 & 0 & 0 & 1 & 0 & 0 & 1 & 0 \\
$\mathbf{0}$ & 1 & 0 & 0 & 0 & 1 & 0 & 0 & 1 & 0 \\
$\mathbf{0}$ & 0 & 0 & 1 & 0 & 0 & 0 & 1 & 1 & 0 \\
$\mathbf{0}$ & 0 & 0 & 1 & 0 & 0 & 0 & 1 & 1 & 0 \\
$\mathbf{1}$ & 0 & 0 & 0 & 0 & 0 & 1 & 0 & 1 & 0 \\
$\mathbf{1}$ & 0 & 0 & 0 & 0 & 0 & 1 & 0 & 1 & 0 \\
$\mathbf{0}$ & 0 & 0 & 1 & 0 & 0 & 0 & 1 & 1 & 0 \\
$\mathbf{1}$ & 0 & 0 & 0 & 0 & 0 & 1 & 0 & 1 & 0 \\
$\mathbf{1}$ & 0 & 0 & 0 & 0 & 0 & 1 & 0 & 1 & 0 \\
$\mathbf{1}$ & 0 & 0 & 0 & 0 & 0 & 1 & 0 & 1 & 0 \\
$\mathbf{1}$ & 0 & 0 & 0 & 0 & 0 & 1 & 0 & 1 & 0 \\
$\mathbf{1}$ & 0 & 0 & 0 & 0 & 0 & 1 & 0 & 1 & 0 \\
$\mathbf{1}$ & 0 & 0 & 0 & 0 & 1 & 0 & 0 & 1 & 0 \\
\end{tabular}

Dataset yang terdiri 500record data dan berisi variabel-variabel atribut disimpan ke dalam Microsoft Excel, dalam tabel ini yang terdapat item yang terpilih akan bernilai satu jika tidak ada variabel akan bernilai nol begitu sterusnya sampai proses tindakan terakhir. Seperti terlihat pada Tabel 2

Setelah didapatkan hasil dari transormasi data dengan berbentuk 0 dan 1 maka langkah selanjutnya buka tampilan design di aplikasi rapid miner seperti pada Gambar 1:

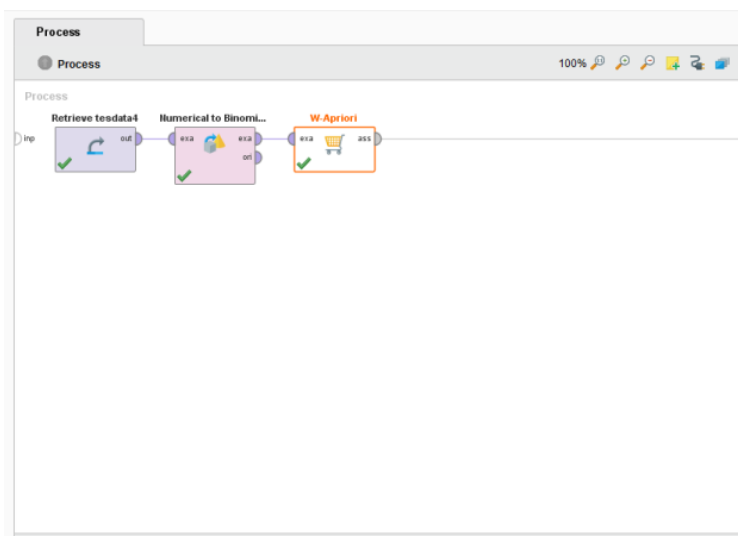

\section{Gambar 1. Desain Rapid Miner}

Dari aplikasi rapid miner ini algoritma association rule dengan metode Apriori akan diproses secara bersamaan untuk itu nilai confidence dan support harus ditentukan terlebih dahulu seperti yang dapat kita lihat pada gambar 2

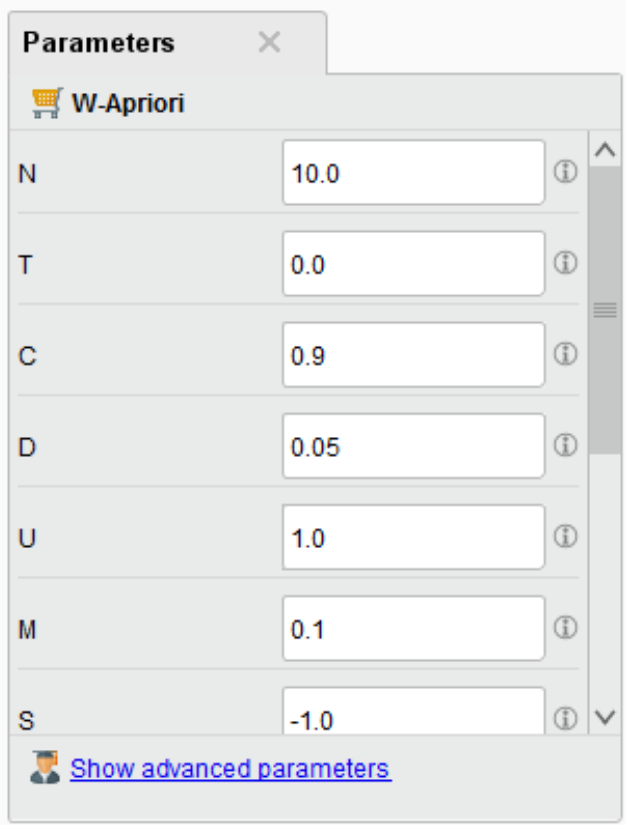

Gambar 2. Nilai Confidence dan Support

Setelah semua ditampilkan maka dijalankan dan akan didapatkan rule-rule seperti Gambar 3 


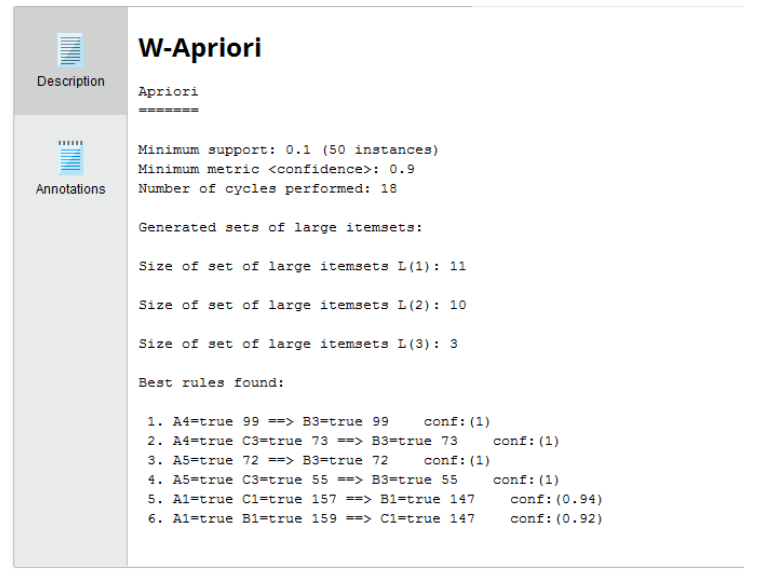

Gambar 3. Asosiasi Rule

\section{PENUTUP}

Dari rule-rule yang sudah dihasilkan sebelumnya apabila rule tersebut diuji ke data sampel mahasiswa baru yang terdiri dari 500 data , maka hasil pengujian yang dilakukan adalah sebagai berikut:

1. Jika mahasiswa berasal dari SMK $\mathrm{N}$ Kendal dan mengambil Kejuruan maka nilai confidence nya sama dengan $100 \%$ didukung 19.8\% dari data keseluruhan.

2.

3. Jika mahasiswa berasal dari SMK $\mathrm{N}$ Kendal dan mengambil kejuruan maka prodi yang diambil adalah TI dengan confidence $\quad 100 \%$ didukung $14.6 \%$ dari data keseluruhan.

4. Jika mahasiswa mengambil kejuruan berasal dari SMK Texmaco dan maka nilai confidencenya $100 \%$ dengan didukung $14.4 \%$ dari data keseluruhan.
5. Jika mahasiswa berasal dari SMK Texmaco dan mengambil kejuruan maka prodi yang diambil adalah TI dengan confidence $\quad 100 \%$ dengan dukungan $11 \%$ dari data keseluruhan.

6. Jika mahasiswa berasal dari SMA N 8 Semarang dan prodi yang diambil adalah Komputerisasi Akuntansi dengan 31.4\%, berasal dari jurusan IPA $29.4 \%$ dari data keseluruhan maka nilai confidence $94 \%$

7. Jika mahasiswa berasal dari SMA N 8 Semarang dengan jurusan IPA sebanyak 31.8\% dan mengambil Komputerisasi Akuntansi 29.4\% maka nilai confidence nya $92 \%$ 


\section{REFERENCES}

Azimah, A., \& Sucahyo, Y. G. (2007). Penggunaan Data Warehouse Dan Data Mining Untuk Data Akademik Sebuah Studi Kasus Pada Universitas Nasional. Jurnal Sistem Informasi MTI UI Vol. 3 - No. 2 - Oktober 2007 , 1-7.

Febryantahanuji, Sembiring, I., \& Purnomo, H. D. (2018). Pengambilan Keputusan Pegawai Tidak Tetap Menjadi Pegawai Tetap Dengan Decission Tree. Journal of Informatics Education , 99-110.

Iko, P. (2006). Pengantar Data Mining : Menambang Permata Pengetahuan di Gunung Data.

Kang, M. K. (2016). Market Basket Analysis: Identify the changing trends of market data. Procedia Computer Science , 78-85.

Kurniawati, A. (2014). Pemetaan Pola Hubungan Program Studi Dengan Algoritma Apriori. Edu Komputika Journal , 51-58.

Luthfi, K. \&. (2009). Algoritma Data Mining. Yogyakarta: Andi Publisher.

PDDIKTI. (2019, 8 12). PDDIKTI. Retrieved 8 12, 2019, from PDDIKTI: https://forlap.ristekdikti.go.id/perguruantinggi/homegraphpt

Prayitno. (2017). Ekstraksi Pola Hubungan Penerimaan Mahasiswa Baru Dengan Sebaran Wilayah Asal Sekolah Menggunakan ARM Algoritma Apriori. Jurnal Teknik Informatika dan Sistem InformasiVolume 3 Nomor 1 April 2017 , 46-56.

Purwanti, D. W. (2018). Analisis Data Mining Dengan Algoritma Fp-Growth. Jurnal SIMTIKA Volume 1, No 1, September 2018/ , 27-31.

Risky, H. \&. (2017). Penerapan Data Mining menggunakan Association Rule Untuk Mendukung Strategi Promosi Universitas Nusantara PGRI Kediri. Seminar Nasional Teknologi Informasi, Komunikasi dan Aplikasinya Volume 04, Tahun 2017 (pp. 138-142). kediri: SEKOLAH TINGGI INFORMATIKA DAN KOMPUTER INDONESIA (STIKI) MALANG. 
Rumaisa, F. (2012). Penentuan Association Rule Pada Pemilihan Program Studi. Seminar Nasional Aplikasi Teknologi Informasi 2012 (SNATI 2012). Yogyakarta: Universitas Islam Indonesia.

Suharyadi, \& Sediyono, E. (2017). Metode Microsoft Clustering untuk Meningkatkan Potensi Penerimaan Mahasiswa Baru .JURNAL SISTEM KOMPUTER , 37-48.

Vaidya, J., \& Clifton, C. (2002). Privacy Preserving Association Rule Mining in Vertically. KDD '02 Proceedings of the eighth ACM SIGKDD international conference on Knowledge discovery and data mining (pp. 639-644). New York: ACMDL.

Yani, H., \& Jusia, P. A. (2018). Penerapan Association Rule Untuk Mendeskripsikan Pola Hubungan Antara Kota Kelahiran Mahasiswa Dengan Tingkat Kelulusan Mahasiswa Pada Stikom Dinamika Bangsa Jambi. Seminar Nasional Sistem Informasi 2018, 9 Agustus 2018 (pp. 1097-1104). Malang: Fakultas Teknologi Informasi - UNMER Malang. 
Haryo Kusumo ${ }^{1}$, Eko Sediyono $^{2}$, Marwata Marwata ${ }^{3}$

This page intentionally left blank.

62 | WJIT : Walisongo Journal of Information Technology 